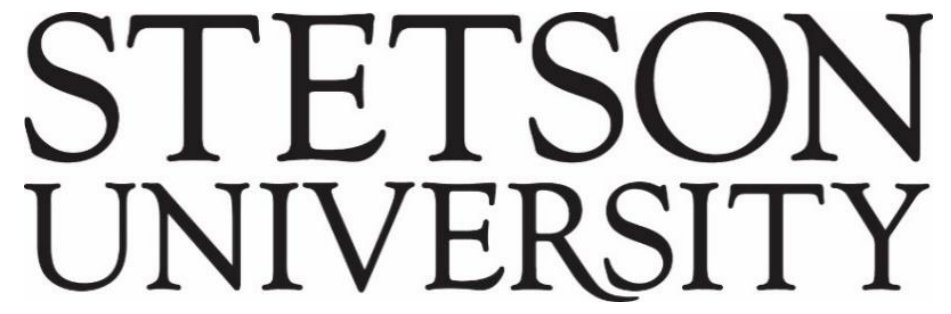

Voices of Reform: Educational Research to Inform and Reform

Volume $3 \bullet$ Issue $1 \bullet$ Article 7

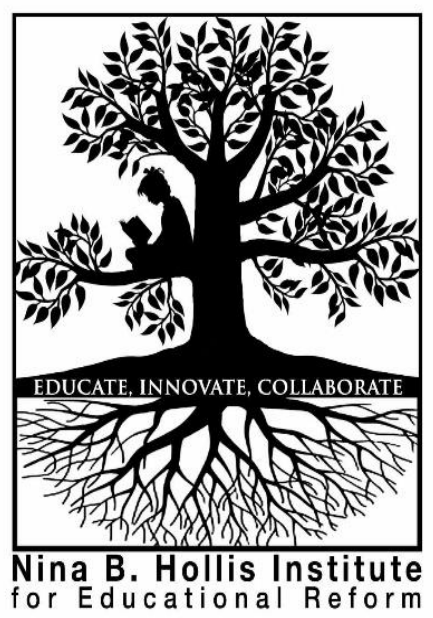

May 2020

\title{
Book Review: Leading Equity-Based MTSS for All Students
}

Joyce Mundy

Delaware County Intermediate Unit

Follow this and additional works at: http://www.voicesofreform.com

Recommended Citation

Mundy, J. (2020). Book review: McCart and Miller: Leading equity-based MTSS for all students. Voices of Reform, 3(1), 136-138. Retrieved from https://www.voicesofreform.com/article/12776-book-review-leading-equitybased-mtss-for-all-students doi: 10.32623/3.00009

http://dx.doi.org/10.32623/3.00009

Revisions

Submission date: February $25^{\text {th }}, 2020$

Publication date: May $1^{\text {st }}, 2020$ 


\title{
Book Review: McCart and Miller: Leading Equity-Based MTSS for All Students
}

\author{
Joyce Mundy ${ }^{1}$ \\ ${ }^{1}$ Director of Curriculum, Instruction, and Planning \\ Delaware County Intermediate Unit, United States \\ jmundy@dciu.org
}

\section{Review}

In the past decades of accountability, schools have adopted multiple iterations of tiered intervention systems such as RTI, RTII, and now MTSS. Data teams and instructional support are a priority in our work. Despite ongoing efforts, it remains a complex challenge to effectively meet the needs of all students. Additionally, schools are now charged with understanding and addressing equity and access gaps in our schools. Leading Equity-Based MTSS for All Students shares practices that are defined in the SWIFT (Schoolwide Integrated Framework for Transformation) Education Center's approach to an equity-based system of support.

The Introduction and Section 1 remind us that "Building effective schools is a persistent, fluctuating task that does not allow for much pause in the process" (p. 2). This has become even more complex as schools address equity and access for students who are systemically marginalized because of race, culture, trauma, economic status, and LGBTQ+ identification. Administrators in the field are finding that creating and sustaining systems that work for all students is at the forefront of their agendas. This text could be an excellent resource for school leaders to utilize in addressing that goal.

The Introduction frames the discussion by asserting that a critical step in transforming MTSS efforts is to challenge embedded past practices and beliefs. Special education and intervention efforts have utilized deficit models as evidenced in the term disabilities. As schools plan more intensive interventions, this deficit model can result in academic silos and unproductive labeling of students. The book encourages a dramatic shift which captures the research on more inclusive practices for all students. Chapter 1 sets the stage with foundational work and "new construction." The framework of an equity-based approach to MTSS is clearly defined, and this becomes the context and roadmap for the subsequent chapters. The authors clarify that we use the terms equity and MTSS frequently, but have difficulty operationally defining how they are enacted. This 
portion of the book could help administrators lead critical conversations with stakeholders on equity-based MTSS. Chapter 2 establishes a matrix that is more robust than the typical 1-2-3 triangle for tiered interventions to which we are accustomed. Chapter 3 moves from constructing a model to engineering the newly created model. This section revisits the "why" and the "what" and moves to the development of a master schedule that meets the goals defined in an equity based MTSS model. This can be a difficult task, but the chapter outlines clear steps to analyze and revise a school's schedule. Chapter 4 is an opportunity for teams to align their new model to existing resources and data routines. There are scenarios and resources to support teams in horizontally and vertically aligning priorities and processes so that the model is solidly built for implementation. Lastly, the Conclusion reminds teams to return to the "why" that they started with, examine the "what" and "how" that they constructed, and commit to fidelity checks moving forward.

There are three things that makes this text extremely valuable. First, McCart and Miller are extremely clear on why MTSS and equity must be integrated to achieve results for all students. Schools can often get detoured in this conversation because it seems so daunting. The authors present clear evidence that can assist leadership teams in doing focused, strategic work. This text can support schools in creating a comprehensive MTSS framework with an embedded equity emphasis. This is achieved through an integrated content and service delivery component which considers not only academic competencies, but also behavioral and social-emotional competencies. Rather than viewing equity as a related priority, the model embeds direct connections in multiple ways for the varied needs of all students. A second strength of this text is that it can be an excellent vehicle for instructional leaders to build a shared vision with their faculty and staff. The clear and concrete steps could frame a professional learning community to examine research, establish a shared vision, plan strategic implementation, and continuously adapt for sustainability. Lastly, and most importantly, it very clearly addresses how our current MTSS models are deficit-based and built on a construct of disabilities. Leading Equity Based MTSS for All Students is a clearly articulated guide for educators and administrators to consider how to effectively meet the needs of every student by synthesizing critical work being done in the areas of Multi-Tiered Systems of Support (MTSS) and equitable practices in our schools.

\section{References}

McCart, A., \& Miller, D. (2020). Leading equity-based MTSS for all students. Thousand Oaks, CA: Corwin Press. 